\title{
Applied Research on Steps of Vocal Music Teaching
}

\author{
Lingyi Li \\ Public Art Education Department \\ Huanghe S\&T College \\ Zhengzhou, Henan, China, 450005 \\ e-mail: 741673583@qq.com
}

\begin{abstract}
Vocal music teaching can be divided into three steps as regulation first, technique second and reprocessing according to the general vocal music teaching theory and practise. Regulation is to balance all the functional organizations in the singing practise in order to reflect the willness of the singer. Technique is to maser the skills effectively in the procedure of singing. Procession is to analyze the music works in order to express the works' style and connotation of the works accurately. For vocal music teaching, only in this way and sequence can the teaching rules be mastered and the outstanding teaching effect can be achieved.
\end{abstract}

Keywords-vocal music teaching; regulation first; technique second; reprocessing

\section{INTRODUCTION}

Vocal music teaching is a process emphasizing to cultivate the students' scientific vocal method and accurate articulation, showing the connotation of the music product by sound, and improving the students' singing ability and artistic accomplishment. [1]

Considering the following differences of each student, as the voice condition and characteristics, singing level and existing problems, the ability of understanding and their artistic accomplishment especially the musical quality, teaching vocal music is distinctively individual, apparently different from the other subjects. Therefore, vocal music teaching in colleges and universities is adapted mostly "one to one" mode, class lectures and group teaching taken as supplement, and there are no unified teaching textbooks for vocal music teaching.

Teachers' ideas and methods are from their former teachers, there is no common sense on vocal music teaching and vocal music technology theory. Without a scientific theory system, in order to improve the level of vocal music teaching theory, I carefully summarize and analyze experiences in vocal music teaching recent years, and adapt the western vocal music teaching theory "regulation first, technique second, reprocessing" to vocal music teaching by innovation, strictly distinguish and master the content of each teaching process, the internal relations and the application in the whole teaching and therefore a relatively perfect teaching application system is formed, which clarificates the teaching idea, and we get good teaching effects accordingly. Some of our opinions and analysis will be discussed in the following.

\section{SignifiCANCE OF Dividing The Vocal Music TEACHING PROCESS}

Vocal music teaching is the art of a strict and scientific teaching category, vocal music teaching should follow the teaching rules with the base on the consideration of physiological and psychological characteristics. The significance is to follow scientific principles of vocal music teaching, to clarificate the teaching ideas, to arrange the teaching content and achieve the goal of individualized vocal music teaching.

From the point of general vocal music teaching theory and practice, vocal music teaching can be divided into three processes as "regulation first, technique second, and reprocessing", Regulation is to regulate all the physical functions participating in the activities of voice singing in order to achieve the state of relative balance therefore consciously react the singers' thoughts. Techniques are effective skills and methods in the singing. Processing is to analyze singing works in order to express the style and the connotation of the works, only with this sequence, can we master the rule of vocal music teaching and achieve better teaching effects.

"Regulation first, technique second, reprocessing" is the sequence of the whole vocal music teaching as well as each class and it plays important role. Regulation, techinque and processing are closely linked to each other as an integral whole, and appear in the whole process of vocal music teaching as well as every class. The typical characteristic is that the importance of each one is not the same at a typical time, it should be in sequence and processed in level so as to improve the teaching effect.

First we need to regulate the student's physical singing functions, cultivate the correct singing voice, and then train students to master correct singing techniques; Finally we analyze and express the works. Regulation is the process of the formation of singing voice, technique is the development of singing voice, processing is the use of singing voice. Therefore, in the whole process of vocal music teaching and every class, the teacher should have the idea of "first "regulation first, technique second, reprocessing", and teach students with purpose, in sequence and efficiently. 


\section{CONTENT OF Vocal Music TEACHING}

The main content of vocal music teaching is to train perfect physiological and psychological condition of singing as singing needs the co-effectS of physiology and psychology. The teaching procedure is divided into two catalogues by the auther according to the demands of physiological and psychological condition, and showed in the following "Table I" "Table II".

TABle I. Physiological Procedures of Vocal Music Teaching
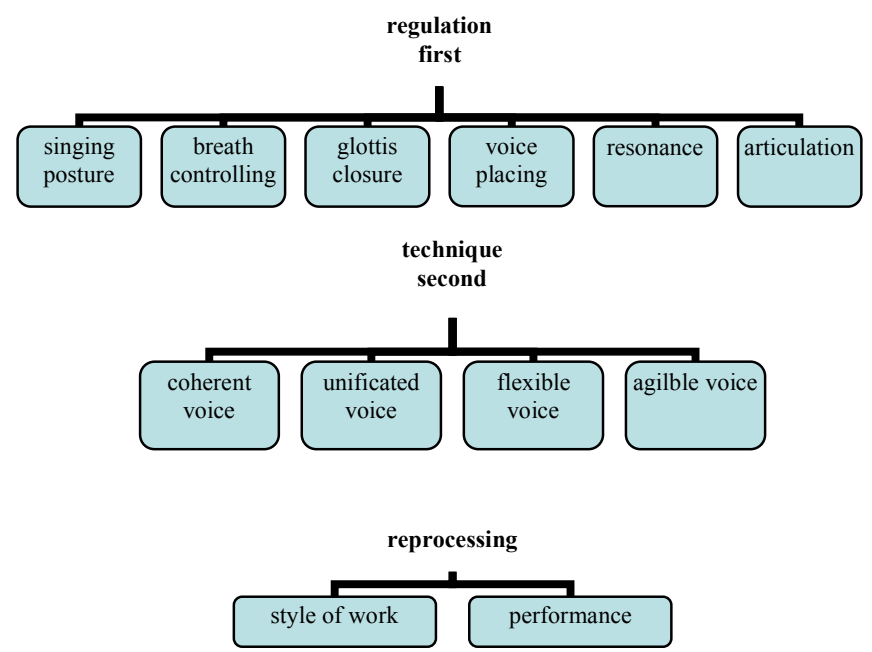

- Singing posture: standing straight, relaxed, smiling and looking at the front.

- Breath controlling: buttocks tight, belly in, deep breath.

- Glottis closure: throat open naturally and stablely, letting the vocal cords capable of regulating expiratory flow.

- Voice placing: narrow the focus of attention of voice on eyebrows.

- Articulation: words out clear and in good voice.

- Coherence, integrity, flexibility, pliability of the voice: having a certain control, the voice out coherent and flexible.

- Style of work: express the tempo, rhythm, speed, language, tone of the song accurately.

- Platform performance: express the figure or the scenery with correct and plentiful body movements.

- Perception: noticing the psychological and physical singing state."

- Vision: focusing the physical and psychological changes state, drawing the virtual songs artistic conception, etc.

- Hearing: listening to the sound effects, considering whether the sound is smooth, firm, bright, relaxed or soft.
- Attention: attention allocation and transferring ability.

- Willpower: good habits of singing.

- Memory: all kinds of emotional memory.

- Involvement: expressing the artistic mood and emotions such as happiness, anger, sorrow, joy, love and resentment.

TABle II. Psychological Procedures of Vocal Music Teaching
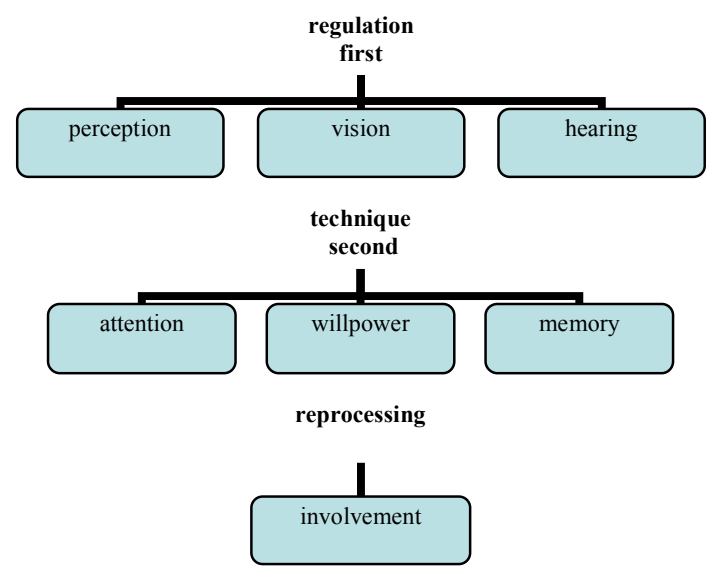

\section{CONCRETE APPLICATION OF STEPS OF VOCAL MUSIC TEACHING}

\section{A. Regulation First}

Regulation is the most complicated teaching process in vocal music teaching, during which the teacher needs to help the students get familiar with all the involving elements and their function and know how to use them such as the standing posture, breath controlling, glottis closure, voice placing, resonance, articulation, perception, vision and hearing.

Standing posture: Correct standing posture is a good reflection of singer image, and the premise to master other singing factors, it will affect the breathing in singing and sound producing and the mutual cooperation between them. Therefore, in vocal training, first thing is to ask students to learn the correct posture. Chinese opera actors in the posture training emphasizes that standing there like a pine as there is a bowl on the head with straight back and chest, relaxed, clear and gazing far " [2] (12) this is the correct expression for singing posture all singing performers need to take this as a reference.

Breath controlling: Breath controlling is the basic of singing. It is very important to master breath controlling. There is a saying of "Ti Shen" in China opera about how to control breath while singing, that is "stretching chest calmly with elbow down and shoulder relaxed, the breath will be controlled perfectly.

Glottis closure: Sound is coming from the vibration of vocal cords. When the golotiis is closed firmly, the sound will be focused and the voice out will be more clear. Glottis closure is a must in all kinds of singing. Ethnic vocal music is to pull vocal cords tight, the strength of closure putting on the former 
place of vocal cords in order to have bright and focused sound. Belcanto is to put the strength on the latter part of vocal cords in order to have gentle, relaxed and flexible sound. [3] (30-41)

Voice placing: The concept of voice placing is mentioned frequently recent years. It emphasizes letting the voice coming from the head, and feeling coming out of the latter place of the head, Putting voice in the former voice in front means the sound of singing focuses on the face, makeing the sound very penetrating. Feeling back is provided by the hindbrain reinforcement effect, full play of vocal fold, producing a rich sound. Therefore, teachers need guiding students to sing with the voice on the high position of the front and upper place, and have the resonant channel turning backwards, to ensure sound bright and smooth.

Resonance regulation: Regulation of resonance is a process to master singing channel. Resonance organ of the human body is a part of the human respiratory organs, consisting of five cavities: chest (trachea, bronchi), laryngeal pharynx, cavum oropharyngeum, nasopharyngeal cavity (various sinus of the skull). These mutually communicated cavities form the respiratory passage. While singing, people use the cavity of the respiratory passage to vibrate and increase the faint pitch resonance of the vocal cords to form the resonance of the singing voice. A good singing voice needs five cavity resonance to be used together. Therefore, it is very important to fully open the throat, to maintain a solid stable laryngeal position and to ensure smooth singing channel.

Articulation: Regulating the articulation is to regulate the throat, tongue, palate and pharynx. When it is appropriate to use the focal point of the tongue, articulation will be clear, beautiful and, accurate. Enunciation is to use the focal point of the tongue at $1 / 3$ or $2 / 3$ point to prevent oral breath. As for Italy bel canto, articulation happens at $2 / 3$ of the anterior tongue, And for Chinese language, the front of the tongue is used often, while singing, people use short consonants and lengthening vowel, and slid over the last words. In addition to the tongue, we also need to make good use of the throat, the palate and pharynx. For Chinese singing, it is very exquisite for articulation.

Perception: "Perception is the overall reflection on attribute of individual objective things, each part and their relationship" [4] (114). Vocal music is called temporal auditory vocal art, because the voice is concerning with time, space and motion, perception such as size, shape, distance, direction and position. Sound from the melody form the beauty of hearing, the singer in the melody need to control the time perception, rhythm, beat and speed; and to regulate the movement and space perception, generateing the beauty of sound and rhythm.

Hearing: Hearing is also a very important factor, as we need hearing to know the rise and fall and the strength of the voice, and the different representation of timbre. When the singer hearing his own voice, they need to have the internal and external auditory consciousness, with the internal auditory consciousness the most important since singers and audience have different reflect on external sound. Singers and the audience have subjective and objective contradictions in hearing. Therefore, singers need to understand the subjective and objective difference of the voice, and adapt to the contradictions, learn to use good sing "hearing" to monitor, adjust, gradually improve singing ability.

Vision: Singing should have auditory sense as well as visual sense, first, reasonablely allocate the quality of the voice to get soft and fruity artistic temperament by the internal and external visual imagery, second, use the words for imagination to creat virtual visual images, vividly express the ideological content of the word.

\section{B. Technique Second}

Technique as the second part of vocal music teaching, the main teaching purpose is to cultivate students good singing voice control ability, such as openning throat freely under control to ensure purity of the singing voice; Control breath by the speed to guarantee the sound soft and bright; Control of diction, guarantee the clear pronunciation and mellow voice, singing language clear, etc. Skill training phase, the singer should have good judgment, the purpose of singing and selfmotivated, various psychological instruction is more accurate, sound has certain expression. In vocal music teaching only when the voice having a certain expressiveness, can we talk about works' processing.

\section{Reprocessing}

Reprocessing of vocal music teaching, the first is to understand the characteristics of the different style of the works, and then get to know the performance way, such as in the national vocal music, southern folk songs exquisite and sweet like " beautiful taihu ", northern folk song high and resounding like "Gan Sheng Lin", Mongolian folk songs enthusiastic, bold and melodious like "hymn", Tibetan folk simple, loud like "toasting song". These works have particular characteristics, reflecting the local people's temperament and life. In order to accurately express the different style of work, we need to further learn the song's performance means, such as tones, port, embellish cavity, emotional line etc. The singing tone can be soft or hard, reflecting the different mood, emotion, showing the mood such as happiness, anger, sorrow and joy; Port is a batch of language expression to emphasize or convert the tone mood and emotion. Accurate port will bring more clear semantic expression and more appropriate emotionand feeling expression. Cavity is most characteristic, works from different regions and different nationalities have unique cavity habits, mostly for different forms of graces, such as appoggiatura, glide, echo, boeing, vibrato etc. For example, many southern folks have appoggiatura, many northern folks have glides, mongolian folks have boeing grace, many Tibetan songs have tremolo grace, which shows that the characteristics of cavity is very significant. General works have three basic expressions and slowing stimulating and introspection phase, slowing is smoothly describing part, more stable and peaceful, stimilating is the climax of the emotion with bold and unrestrained intense mood, introspection is the part of deep and sincere emotion expression with reserved emotion.

\section{CONCLUSION}

In vocal music teaching processing procedure, emotional engagement is the key of singing learning. Use a lot of sound 
techniques without emotional engamement is hard to move the audience, therefore, singers must learn to engage themselves in the singing procedure, putting techniques naturally into the singing emotion, and perform arts wonderfully.

\section{REFERENCES}

[1] Ligang Yang, Vocal Music Methodology [M], Shanghai: Shanghai music publishing house, 2007.

[2] Youkui Huang, Youkui Huang's Vocal Teaching Art [M], Beijing:Huale publishing House, 2003.

[3] Naixian Pan, Vocal Music Teaching Guide [M], Shanghai: Shanghai Music Publishing House

[4] Xiufeng Ding, Psychology [M], Kaifeng:Henan University Press. 1994. 